\title{
Modelling of cutting forces and surface roughness evolutions during straight turning of Stellite 6 material based on response surface methodology, artificial neural networks and support vector machine approaches
}

\author{
B. Ben Fathallah ${ }^{1} 2^{*}$, R. Saidi ${ }^{3}$, S. Belhadi ${ }^{4}$, M. A. Yallese ${ }^{4}$ and T. Mabrouki ${ }^{2,3}$ \\ ${ }^{1}$ Mechanical, Material and Process Laboratory (LR11ES19), ENSIT - University of Tunis, 5 AV Taha Hussein Montfleury, Tunis Tunisia \\ Phone: +21658495479; Fax: +21671872729 \\ 2 ENIT, University of Tunis El Manar, BP 37, Le Belvédère, 1002 Tunis, Tunisia \\ ${ }^{3}$ Applied Mechanics and Engineering Laboratory (LR-11-ES19), University of Tunis El Manar, ENIT, BP 37, Le Belvédère, 1002 Tunis, Tunisia \\ ${ }^{4}$ Mechanics and Structures Research Laboratory (LMS), May 8th 1945 University, P.O. Box 401, 24000 Guelma, Algeria
}

\begin{abstract}
The present research work proposes an experimental investigation helping to comprehend fundamental impacts of operating conditions during the cutting of cobalt alloys (Stellite 6). Thus, an experimental design was adopted to allow to build predicted mathematical models for the outputs, which are the average peak-to-valley profile roughness $\left(R_{z}\right)$ and the tangential cutting force $\left(F_{t}\right)$. Artificial neural network (ANN), support vector machine (SVM) and response surface methodology (RSM) were exploited to model the pre-cited outputs according to operation parameters. As a result, it has been highlighted that both feed rate and cutting depth, considerably, affect tangential cutting force evolution. Moreover, results show that both the insert feed rate and nose radius, are higher. This means the average peak-to-valley profile roughness is higher. In order to put out the effect of operating parameters on cutting outputs, Analysis of variance (ANOVA) method has been employed. This has allowed the detection of significant cutting conditions affecting average peak-to-valley profile roughness and tangential cutting force. In fact, to highlight the performance of adopted mathematical approaches, a comparison between RSM, ANN, and SVM has been also established in this study.
\end{abstract}

ARTICLE HISTORY

Received: $19^{\text {th }}$ Dec 2019

Revised: 22nd June 2021

Accepted: $28^{\text {th }}$ June 2021

\section{KEYWORDS}

Stellite 6;

turning;

RSM;

ANOVA;

ANN;

SVM.

\section{INTRODUCTION}

Cobalt alloys are largely used in the aerospace industry for many applications to require an excellent mechanical strength, corrosion and oxidation resistance at high temperatures $[1,2]$. This super-alloys is specially used for nuclear reactors, electronics and chemical equipment and medical devices principally in power plants $[3,4]$.

Nevertheless, the cobalt alloy is known by machining difficulties [5]. The principal problems encountered in the dry machining of cobalt alloys are low material removal rates and the reduction of tool life. The low thermal conductivity and a strong chemical bond for various materials cause frequently the formation of an adhesion layer on the cutting face yielding to a rapid tool wear. Moreover, the low elastic modulus of cobalt alloy (50\% lower than steel) is the most significant source of vibrations generated during machining. In addition, this material is sensitive to mechanical and thermal shocks due to their reduced toughness [6]. The grain size and presence of carbide formed in the Cobalt matrix of the cobalt based super alloy present a significant change in mechanical properties [7].

The chrome element is a component of cobalt alloy. It improves its resistance to hot corrosion under room temperature. Moreover, in machining of cobalt alloy, the thermal and mechanical interaction of tool-workpiece generate the mechanical and microstructural change at the sub-surface and their impact on fatigue life $[8,9]$. The cutting difficulties in the machining of cobalt alloy is related to their intrinsic characteristics and high hardness. These characteristics lead to a Short-lived tool and a deterioration of the machined surface [10]. As a result, significant changes in surface layers, caused by metallurgical transformations, may occur during the tool-material interaction [11-13]. Such transformations depend on the cutting process parameters, thermo-mechanical properties of workpiece material, the shape and grade of the tool and the cooling mode $[8,13,14]$.

In the literature, different machining methods and modelling procedures have been proposed by different scientists to optimize conditions. Their objectives have been to ultimately predict the Stellite 6 machinability and to achieve greater efficiency [15-17]. Notwithstanding, to our knowledge, it is important to conduct studies on the effect of machining parameters on the modification of surface characteristics and integrity of cobalt-based alloys. Numerous researchers, Aykut et al. and Saidi et al., $[18,19]$ were interested in finding the optimal cutting conditions when machining cobaltbased refractory materials. Bagci et al. and Aykut et al., [20, 21]. looked in up or down face milling of cobalt alloy (Stellite 6 ), the influence of machining conditions on tool wear during, tangential force $\left(F_{t}\right)$ and chip morphology.

In milling of Stellite 6, using Taguchi method, Bagci et al., [16] have investigated the influence of cutting parameters on surface roughness [22]. It is revealed that surface roughness values are strongly influenced by feed rate speed, cutting 
speed and cutting depth [16, 17, 23]. The contribution of Bordin et al., [13] show the effect of cutting parameters with PVD TiALN under conventional lubrification conditions in the cobalt alloy (CoCrMo) turning. It has been discovered that the feed rate represent the most parameter affecting the integrity and surface quality and tool wear mechanisms. Turning and milling processing of the cobalt alloy reduce tangential cutting forces; As a result, they maintain its hardness and mechanical strength. Nevertheless, this is uncertain depending on the variation in cutting speed [19]. Yingfei et al., [12] observed a compressive residual stress along feed rate direction when machining longer than 5 min are converted to a tensile residual stress along cutting one with all cutting conditions. However, the microhardness on surface and subsurface layers, affected by cutting parameters reveals higher values. These increases were caused by the contact between the interaction tool-workpiece [12, 13].

To attain production efficiency, various modelling methods and techniques have been applied to optimize cutting conditions [14, 16, 19]. Artificial neural networks (ANN), genetic algorithm (GA), genetically optimized neural network system (GONNS) and other modelling techniques are adopted to optimize machining operations with the response surface methodology (RSM) [24, 25]. In order to compare the dry to cooling mode in turning Stellite 6, Sarikaya et al., [14, 17] examined the influence of these parameters on tool wear based on Analysis of variance (ANOVA) and Taguchi methods to determine optimal surface roughness. Sarikaya et al., [26] have inspected the cooling mode optimization with MQL method (Minimum Quantity Lubrication) using Taguchi method and Grey relational analysis in turning of cobalt based alloy (HAYNES 25).

Two methods support vector machine (SVM) and ANN are used by many authors for correlations between response and process parameters. Among the kernel methods, it can be found the inspired statistical theory of learning by Vladimir and Vapnik, [27-30] SVM approach is the most well-known form. It is based on the existence of a linear classifier in an appropriate space. In studies Boser et al., Cortes and Vapnik, [31, 32]. and his co-authors [29] introduced carrier vector machines (SVMs) as non-linear extensions of a linear separator: the maximum margin hyperplane [33]. Much works has been completed in the field of speech recognition by applying SVM and several kernels are being developed for this purpose [33-35]. Vadlamani et al. and Mohammadnejad et al., [36, 37] have used the SVM method to predict the induced ground vibration. These experimental data was used by authors to generate the SVM model. Thesebpredicted results corroborate ones with correlation coefficient of 0.944 .

The research conducted by Rao Venkata et al., [38, 39] have shown that ANN technique can help in the selection of appropriate cutting parameters minimizing tool vibration, insert wear and reducing surface roughness. De Aguiar et al., [40] have studied the hardened steel grinding process and observed a slight increases of surface roughness with cutting parameters. Indeed, Ben Fathallah et al., [24] investigated multi-objective optimization in turning of AISI 12L14 freecutting steel for an appropriate combination of settings to obtain optimal surface quality and productivity, such as (surface roughness, material removal rate, and etc.).Belhadi et al., [41] studied the optimization of the orthogonal high density polyethylene (HDPE-100) turning operation using (GRA) technique. It is found the feed rate has significantly effect on tangential force than cutting depth and cutting speed.

Based on previous studies, it appears important to perform scientific research to characterize the machinability of cobalt alloy commercially named Stellite 6. Our study focuses on the establishment of cutting models modelling allowing to predict the evolution of process responses such as the average peak-to-valley profile roughness $\left(\mathrm{R}_{\mathrm{z}}\right)$ and the tangential force $\left(F_{t}\right)$ according to finishing cutting conditions. For that, response surface methodology (RSM), artificial neural network (ANN), support vector machine (SVM) and ANOVA analysis were exploited.

\section{METHODOLOGY}

\section{Experimental Setup and Turning Conditions}

Our machined parts are based on the cobalt alloy (Stellite 6), with a chemical composition including $28.25 \% \mathrm{Cr}, 3.74$ $\% \mathrm{~W} 1.17 \% \mathrm{Mo}, 1.11 \% \mathrm{C}, 1.89 \% \mathrm{Fe}, 2.32 \% \mathrm{Ni}, 0.57 \% \mathrm{Mn}, 1.20 \% \mathrm{Si}, 0.004 \% \mathrm{P}, 0.001 \% \mathrm{~S}$, and balance of Co. This material has an average hardness of 41 HRC. Figure 1 shows that the material microstructure is mainly composed with an intimate lamellar mixture of the fcc alpha phase and $(\mathrm{Cr}, \mathrm{Co}, \mathrm{W}) \mathrm{TC}$ eutectic carbides, which are distributed in coarse plates of $\mathrm{M}_{7} \mathrm{C}_{3}$ carbide and finer particles of $\mathrm{M}_{23} \mathrm{C}_{6}$ carbide. The straight turning operations were performed on three parts. Each one is subdivided on zones separated by grooves, in order to respect the decided combinations for the adopted experimental design (Figure 2). During this study, the cutting parameters (Insert nose radius ( $r$ ), cutting speed $\left(\mathrm{V}_{\mathrm{c}}\right)$, feed rate (f) and cutting depth $\left(\mathrm{a}_{\mathrm{p}}\right)$ ) are presented in Table 1 and the experimental machining are presented in Table 2 . The cutting force was measured by a piezo-electric transducer dynamometer (type Kistler 9257B) and the average peak-tovalley profile roughness $\left(R_{z}\right)$ values were measured by Mitutoyo Surftest type SJ-201P (Figure 2). 
Table 1. Levels and cutting conditions values

\begin{tabular}{ccccc}
\hline & \multicolumn{4}{c}{ Factors } \\
\cline { 2 - 5 } Level & $\begin{array}{c}r \\
(\mathrm{~mm})\end{array}$ & $\begin{array}{c}V_{c} \\
(\mathrm{~m} / \mathrm{min})\end{array}$ & $\begin{array}{c}f \\
(\mathrm{~mm} / \mathrm{rev})\end{array}$ & $\begin{array}{c}a_{p} \\
(\mathrm{~mm})\end{array}$ \\
\hline 1 & 0.2 & 30 & 0.08 & 0.15 \\
2 & 0.4 & 55 & 0.12 & 0.30 \\
3 & 0.8 & 80 & 0.16 & 0.45 \\
\hline
\end{tabular}

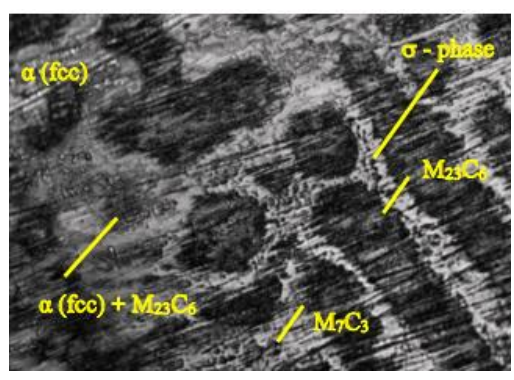

Figure 1. Microstructure of Stellite 6 Cobalt Alloy, (magnification: $\mathrm{x}$ 400)

Table 2. Definition of the experimental machining system

\begin{tabular}{ll}
\hline \multicolumn{1}{c}{ Item } & \multicolumn{1}{c}{ Description } \\
\hline \multirow{2}{*}{ Machine tool } & SN 40C, with 6.6 kW spindle power of the Czech company "TOS \\
& TRENCIN" \\
coated with PVD $(\mathrm{Ti}, \mathrm{Al}) \mathrm{N} 2, \mathrm{CNGG}$, SGF geometry, \\
$(1105$ grade) Sandvik ISO \\
Tool Holder & PCLNR 2020K12 \\
& cutting edge angle $\left(\chi_{r}=+95^{\circ}\right)$, inclination angle $\left(\lambda=-6^{\circ}\right)$, rake angle \\
& $\left(\gamma=-6^{\circ}\right)$ and clearance angle $\left(\alpha=0^{\circ}\right)$ \\
Working tool geometry & nose radius: $0.2,0.4$ and $0.8 \mathrm{~mm}$ \\
Cooling mode & Synthetic conventional oil mode $(20 \%)$. \\
\hline
\end{tabular}

The design of experiments (DOE) was adopted and experimental tests based on 4 factors at 3 levels were carried-out in Table 1. A statistical data processing using Analysis of variance (ANOVA) and Response surface methodology (RSM) method to determine machining parameters relationships and process characteristics. The ANN and SVM were also exploited for modelling outputs process of cutting parameters.

In RSM, relationship between input parameters $\left(r, V_{c}, f\right.$ and $\left.a_{p}\right)$ and responses $\left(\mathrm{R}_{\mathrm{z}}\right.$ and $\left.\mathrm{F}_{\mathrm{t}}\right)$ can be expressed based on the following quadratic polynomial equation (Eq. (1)):

$$
\Phi=b_{0}+\sum_{i=1}^{4} b_{i} X_{i}+\sum_{i=i}^{4} b_{i j} X_{i} X_{j}+\sum_{i=1}^{4} b_{i i} X_{i}^{2}+\varepsilon
$$

Here, $\Phi$ indicates estimated responses $\left(\mathrm{R}_{\mathrm{z}}\right.$ and $\left.\mathrm{F}_{\mathrm{t}}\right), b_{0}$ is a constant term, $b_{i}$ is a linear effect, $b_{i i}$ corresponds to pure quadratic effect, $b_{i j}$ is the second level interaction effects, $X \mathrm{i}$ and $X_{j}$ indicate the associated coded variables $\left(r, V_{c} f\right.$ and $a_{p}$ ) and $\varepsilon$ is the error in predicting experimental on estimated responses. 


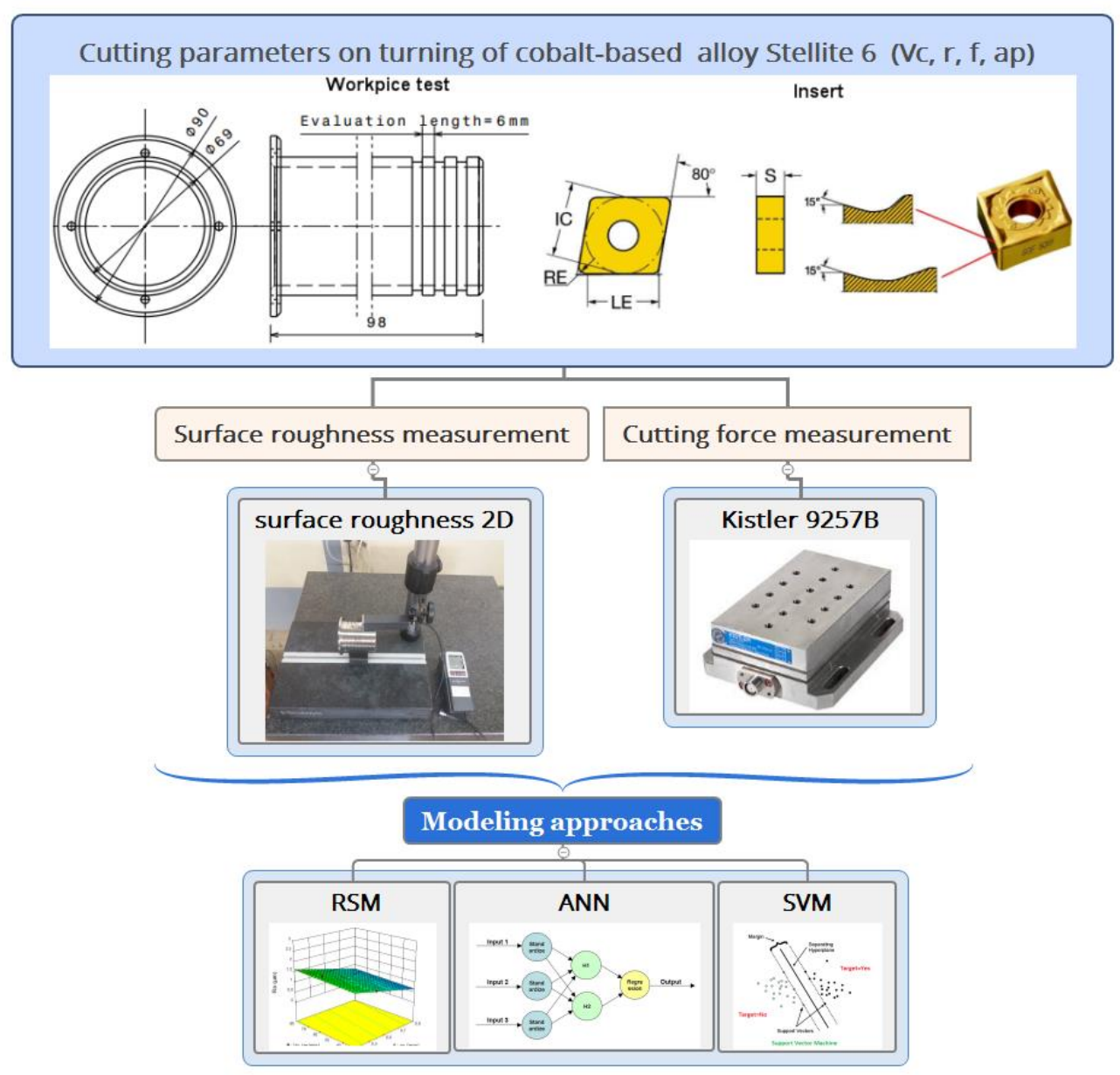

Figure 2. Experimental design diagram used workpiece, tool geometry, acquisition system and modelling approaches: response surface methodology (RSM), artificial neural networks (ANN) and support vector machine (SVM)

\section{RESULTS AND DISCUSSION}

\section{Prediction of Responses using RSM}

Variations on responses are calculated based on factors considered influential, previously. Effects of the combined operating conditions $\left(r, V_{c}, f\right.$ and $\left.a_{p}\right)$ on responses of the cutting force $\mathrm{F}_{\mathrm{t}}$ and the average peak-to-valley profile roughness $\left(\mathrm{R}_{\mathrm{z}}\right)$, in machining of the Stellite 6 cobalt alloy with the turning process, were evaluated. These experimental results are presented in Table 3. For prediction with an empirical modeling approach, we used the response surface methodology (RSM). This technique allows minimizing the number of cutting tests during design optimization. Moreover, the aim of ANOVA analysis is used to specify the significantly affection of the cutting parameters $\left(r, V_{c}, f\right.$ and $\left.a_{p}\right)$ on the responses, $\mathrm{R}_{\mathrm{z}}$ and $\mathrm{F}_{\mathrm{t}}$, respectively. The statistical treatment of the data based on ANOVA method using some equations to evaluate the contribution of input parameters and their interactions. Furthermore, the second phase is based on an quadratic regression using the optimal regression equations characterising $\mathrm{R}_{\mathrm{z}}$ and $\mathrm{F}_{\mathrm{t}}$ models. These models were analyzed by exploiting design expert software to study the impact of cutting conditions $\left(r, V_{c}, f\right.$ and $\left.a_{p}\right)$ on global variance of results.

The results derived from the ANOVA method indicate that the feed rate is the main factor affecting $\mathrm{R}_{\mathrm{z}}$ variations (Table 4) with a contribution of about $48.55 \%$ (Figure 3(a)). The other terms $(r),(r \times f)$ and $(r \times r)$ have a lower contribution with $39.72 \%, 1.19 \%$ and $5.05 \%$, respectively (Figure 3(a)). The results derived from the ANOVA method indicate that the feed rate is the main factor affecting $R_{z}$ variations, ratio of mean square of regression model (F-value) and probability value (p-value) (Table 4) with a contribution of about $48.55 \%$ (Figure 3(a)). Results in Table 5 show that $a_{p}$ is the most significant factor affecting tangential force $\left(F_{t}\right)$ variations with $76.03 \%$ contribution (Figure 3(b)). The next important contributions are $f(10.79 \%), V_{c}(2.91 \%)$ and $f \times a_{p}(2.31 \%)$. 
Table 3. Experimental results of average peak-to-valley profile roughness $\left(R_{z}\right)$ and tangential force $\left(F_{t}\right)$ when varying cutting conditions

\begin{tabular}{|c|c|c|c|c|c|c|}
\hline \multirow[b]{2}{*}{$\begin{array}{l}\text { Trail } \\
\text { No. }\end{array}$} & \multicolumn{4}{|c|}{ Inputs } & \multicolumn{2}{|c|}{ Outputs parameters } \\
\hline & $\begin{array}{c}r \\
(\mathrm{~mm})\end{array}$ & $\begin{array}{c}V_{c} \\
(\mathrm{~m} / \mathrm{min})\end{array}$ & $\begin{array}{c}f \\
(\mathrm{~mm} / \mathrm{rev})\end{array}$ & $\begin{array}{c}a_{p} \\
(\mathrm{~mm})\end{array}$ & $\begin{array}{c}R_{z} \\
(\mu \mathrm{m})\end{array}$ & $\begin{array}{l}F_{t} \\
(\mathrm{~N})\end{array}$ \\
\hline 1 & 0.2 & 30 & 0.08 & 0.15 & 5.11 & 43.0 \\
\hline 2 & 0.2 & 30 & 0.08 & 0.30 & 5.81 & 94.0 \\
\hline 3 & 0.2 & 30 & 0.08 & 0.45 & 6.25 & 147.4 \\
\hline 4 & 0.2 & 55 & 0.12 & 0.15 & 7.46 & 70.0 \\
\hline 5 & 0.2 & 55 & 0.12 & 0.30 & 7.94 & 131.2 \\
\hline 6 & 0.2 & 55 & 0.12 & 0.45 & 6.90 & 218.2 \\
\hline 7 & 0.2 & 80 & 0.16 & 0.15 & 10.65 & 82.0 \\
\hline 8 & 0.2 & 80 & 0.16 & 0.30 & 9.07 & 171.6 \\
\hline 9 & 0.2 & 80 & 0.16 & 0.45 & 10.06 & 262.4 \\
\hline 10 & 0.4 & 30 & 0.12 & 0.15 & 5.09 & 55.5 \\
\hline 11 & 0.4 & 30 & 0.12 & 0.30 & 6.60 & 109.6 \\
\hline 12 & 0.4 & 30 & 0.12 & 0.45 & 6.57 & 183.9 \\
\hline 13 & 0.4 & 55 & 0.16 & 0.15 & 6.44 & 90.5 \\
\hline 14 & 0.4 & 55 & 0.16 & 0.30 & 7.35 & 152.7 \\
\hline 15 & 0.4 & 55 & 0.16 & 0.45 & 7.92 & 259.2 \\
\hline 16 & 0.4 & 80 & 0.08 & 0.15 & 3.07 & 54.4 \\
\hline 17 & 0.4 & 80 & 0.08 & 0.30 & 3.18 & 96.7 \\
\hline 18 & 0.4 & 80 & 0.08 & 0.45 & 3.49 & 175.6 \\
\hline 19 & 0.8 & 30 & 0.16 & 0.15 & 5.96 & 69.3 \\
\hline 20 & 0.8 & 30 & 0.16 & 0.30 & 6.32 & 118.3 \\
\hline 21 & 0.8 & 30 & 0.16 & 0.45 & 6.15 & 208.5 \\
\hline 22 & 0.8 & 55 & 0.08 & 0.15 & 2.98 & 58.4 \\
\hline 23 & 0.8 & 55 & 0.08 & 0.30 & 2.30 & 98.0 \\
\hline 24 & 0.8 & 55 & 0.08 & 0.45 & 3.13 & 150.3 \\
\hline 25 & 0.8 & 80 & 0.12 & 0.15 & 4.43 & 70.4 \\
\hline 26 & 0.8 & 80 & 0.12 & 0.30 & 3.52 & 137.5 \\
\hline 27 & 0.8 & 80 & 0.12 & 0.45 & 4.29 & 207.0 \\
\hline
\end{tabular}

Table 4. Analysis of variance (ANOVA) results for the average peak-to-valley profile roughness $\left(\mathrm{R}_{\mathrm{z}}\right)$

\begin{tabular}{ccccccc}
\hline Source & $\begin{array}{c}\text { Sum } \\
\text { of Squares }\end{array}$ & df & $\begin{array}{c}\text { Mean } \\
\text { Square }\end{array}$ & F-value & p-value & Significance \\
\hline Model & 120.98 & 6 & 20.16 & 64.12 & 0.00 & significant \\
$r$ & 50.56 & 1 & 50.56 & 160.79 & 0.00 & significant \\
$V_{c}$ & 1.16 & 1 & 1.16 & 3.68 & 0.07 & not significant \\
$f$ & 61.79 & 1 & 61.79 & 196.49 & 0.00 & significant \\
$a_{p}$ & 0.716 & 1 & 0.716 & 2.28 & 0.15 & not significant \\
$r \times f$ & 1.52 & 1 & 1.52 & 4.82 & 0.04 & significant \\
$r \times r$ & 6.43 & 1 & 6.43 & 20.44 & 0.00 & significant \\
\hline Residual & 6.29 & 20 & 0.314 & & & \\
Total Corrected & 127.27 & 26 & & & & \\
\hline
\end{tabular}


Table 5. ANOVA results for tangential force $\left(F_{t}\right)$

\begin{tabular}{ccccccc}
\hline Source & $\begin{array}{c}\text { Sum of } \\
\text { Squares }\end{array}$ & df & $\begin{array}{c}\text { Mean } \\
\text { Square }\end{array}$ & F-value & p-value & Significance \\
\hline Model & $1.04 \mathrm{E}+05$ & 10 & 10426.74 & 363.32 & 0.00 & significant \\
$r$ & 582.8 & 1 & 582.8 & 20.31 & 0.00 & significant \\
$V_{c}$ & 3049.63 & 1 & 3049.63 & 106.26 & 0.00 & significant \\
$f$ & 11299.45 & 1 & 11299.45 & 393.73 & 0.00 & significant \\
$a_{p}$ & 79605.18 & 1 & 79605.18 & 2773.83 & 0.00 & significant \\
$r \times V_{c}$ & 187.44 & 1 & 187.44 & 6.53 & 0.02 & significant \\
$r \times a_{p}$ & 385.69 & 1 & 385.69 & 13.44 & 0.00 & significant \\
$V_{c} \times a_{p}$ & 367.52 & 1 & 367.52 & 12.81 & 0.00 & significant \\
$f \times a_{p}$ & 2424.79 & 1 & 2424.79 & 84.49 & 0.00 & significant \\
$V_{c} \times V_{c}$ & 537.45 & 1 & 537.45 & 18.73 & 0.00 & significant \\
$a_{p} \times a_{p}$ & 649,45 & 1 & 649.45 & 22.63 & 0.00 & significant \\
\hline Residual & 459.18 & 16 & 28.7 & & & \\
Total & $1.05 \mathrm{E}+05$ & 26 & & & & \\
Corrected & & & & & & \\
\hline
\end{tabular}

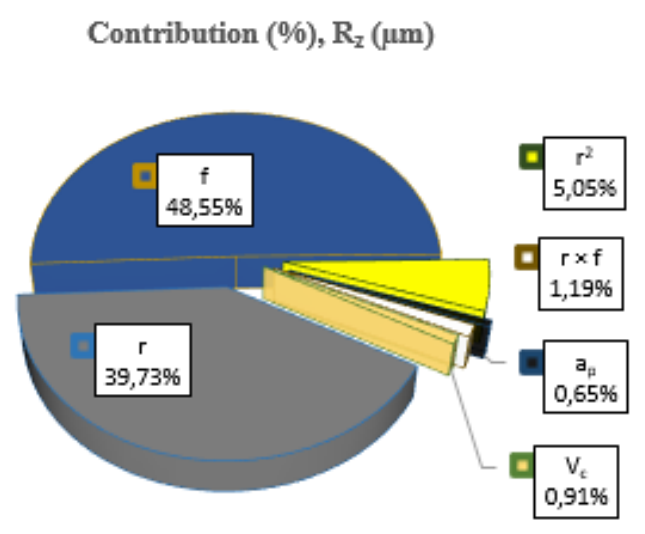

(a)

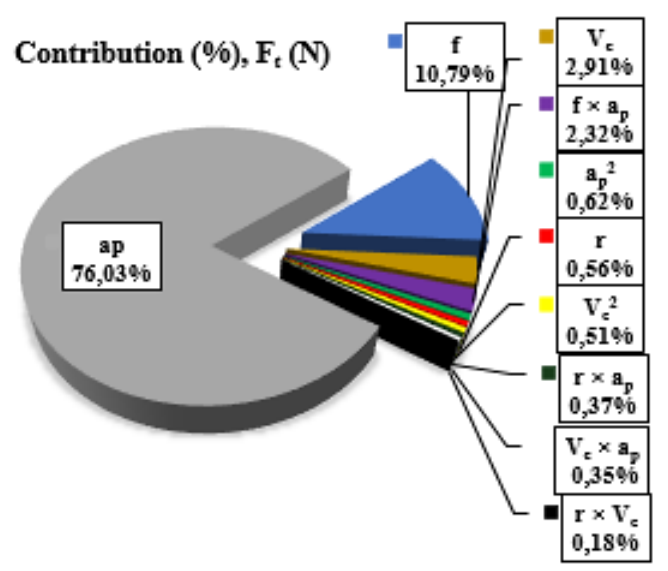

(b)

Figure 3. Contribution of cutting parameters on: (a) the average peak-to-valley profile roughness and (b), tangential force

\section{Regression Equations}

The relationship between cutting parameters and predicted outputs $\left(\mathrm{R}_{\mathrm{z}}, \mathrm{F}_{\mathrm{t}}\right)$ is displayed by quadratic equations (Eqs. (2) and (3)) with coefficients of determination $R^{2}$ equal to $95.06 \%$ and $99.56 \%$, respectively. ANOVA results of $R_{z}$ indicate that $R^{2}$ (squared value) is close to 1 , whereas $R^{2}$ adjusted is equal to 0.94 and $R^{2}$ predicted is equal to 0.91 . In the 
case of ANOVA applied to that $\mathrm{R}^{2}$ is close to 1 whereas both $\mathrm{R}^{2}$ adjusted and $\mathrm{R}^{2}$ predicted are almost equal to 0.99 . Consequently, elaborated quadratic models according to significant input parameters and their interactions are presented by (Eqs. (2) and (3)).

$$
\begin{gathered}
R_{z}=3.48-14.63 \times r-0.012 \times V_{c}+64.09 \times f+1.33 \times a_{p}-34.41 \times r \times f+13.17 \times r^{2} \\
\mathrm{~F}_{\mathrm{t}}=-10.11-15.18 \times r+1.44 \times V_{c}+30.38 \times f-133.76 \times a_{p}+0.61 \times \mathrm{r} \times V_{c}+ \\
-123.71 \times r \times a_{p}+1.47 \times V_{c} \times a_{p}+2369.17 \times f \times a_{p}-0.015 \times V_{c}^{2} \\
+462.39 \times a_{p}^{2}
\end{gathered}
$$

Figures 4 (a) and (b) displays a comparison between measured and predicted responses $\left(R_{z}\right.$ and $\left.F_{t}\right)$. This comparison proves a good corroboration between results. Figures 5 (a) and (b) show the normal probability diagrams of $R_{z}$ and $F_{t}$, respectively. These models are adequate as represented by the points falling in a straight line along the normal probability curve. It indicates that errors are normally distributed. Theses graphics indicate also the capability of quadratic models to predicted values in comparison with the experimental of different technological studied parameters.

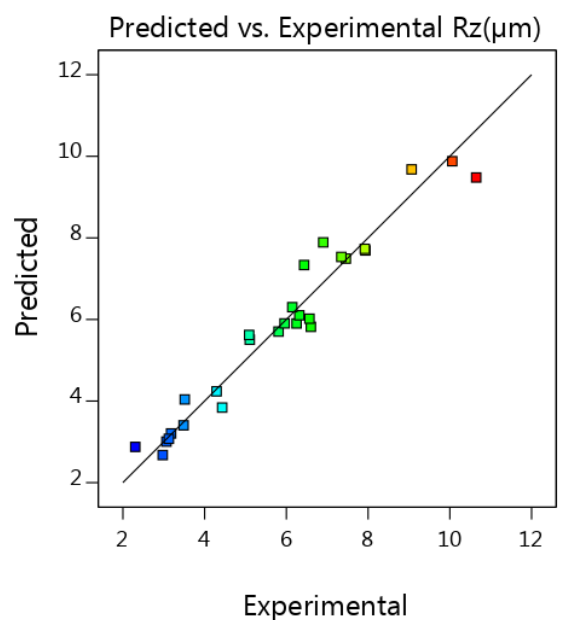

(a)

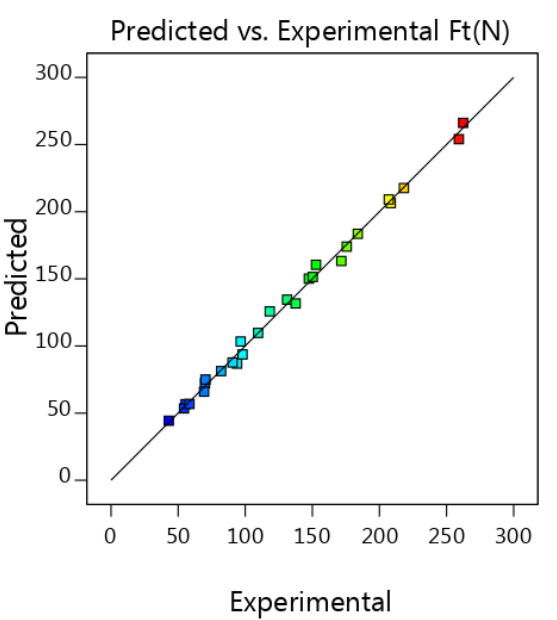

(b)

Figure 4. Comparison between experimental and predicted values of technological parameters: (a) average peak-tovalley profile roughness and (b) tangential force

(a)

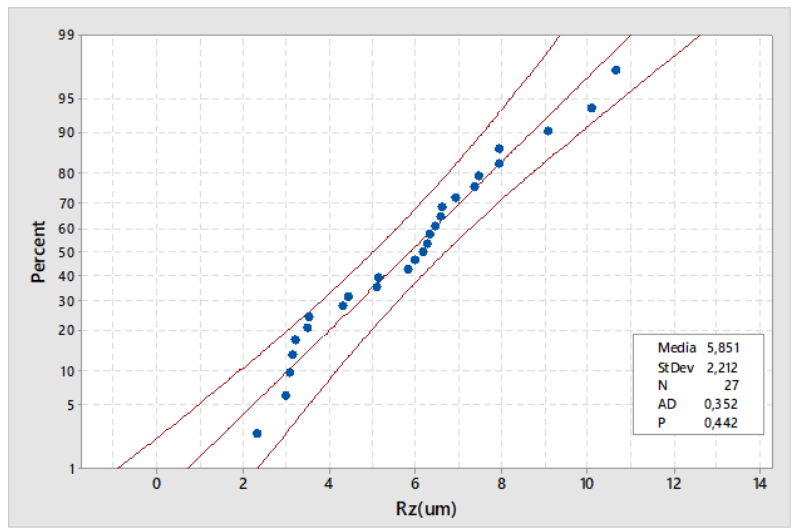

(b)

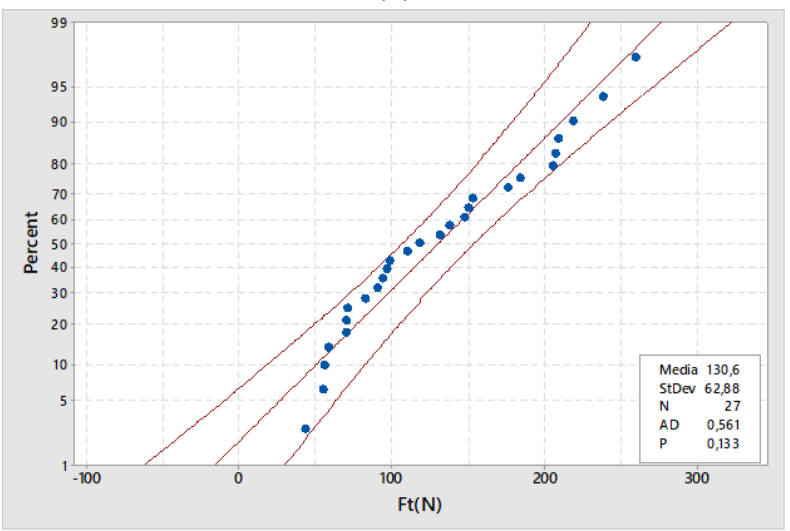

Figure 5. Normal probability plots of: (a) average peak-to-valley profile roughness and (b) tangential force

\section{Effect of Cutting Conditions on $\mathrm{R}_{\mathrm{z}}$ and $\mathrm{F}_{\mathrm{t}}$ Evolutions}

The effect of turning conditions ( $\mathrm{r}, \mathrm{V}_{\mathrm{c}}, \mathrm{f}$, and ap) on machinability and surface quality of Stellite 6 , such us the average peak-to-valley profile roughness, $\mathrm{R}_{\mathrm{z}}$ and the tangential force, $\mathrm{F}_{\mathrm{t}}$ are studied in this reseach. The results of cutting parametters $\left(V_{c}=80 \mathrm{~m} / \mathrm{min}\right.$ and $a_{p}=0.45 \mathrm{~mm}$ ) on resonse $\mathrm{R}_{\mathrm{z}}$ and $\mathrm{F}_{\mathrm{t}}$ are presented in $2 \mathrm{D}$ contours illustrations (Figure 6 , 7 (a) and 7(b)). It has been shown an increase of the microgeometrical characterics for higher nose radius and smaller feed rate (Figure 6). This investigation corroborate to the contribution of Bordin et al. [13]. Furthermore, the effect of

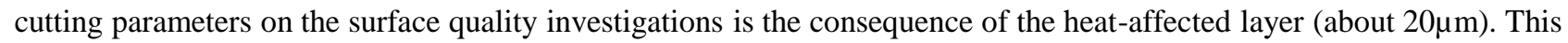
result corroborate to published paper in [8], [9], [42]. Also, the effect of cutting parameters $\left(r, V_{c}, f\right.$ and $\left.a_{p}\right)$ on surface 
integrity such as the tangential force, $F_{t}$ were shown in Figure 7(a). The evolution of $F_{t}$ depends considerably on a and $V_{c}$ variations. This figure depicts higher levels of $F_{t}$ as the cutting depth and feed rate increases. Lower $F_{t}$ values are depicted when both feed rate and cutting depth are decreasing. This is the results of lower chip section. For cutting parameters $V_{c}=80 \mathrm{~m} / \mathrm{min}$ and $f=0.12 \mathrm{~mm} / \mathrm{rev}$ a slight effect of the nose radius on tangential force evolution can be underlined (Figure 7(b)). Important values of $F_{t}$ are shown for higher cutting depth of nose radius, independently. Higher $F_{t}$ values are due to material hardening caused by higher cutting depth $[13,18]$.

Figure 7(c) shows a small effect of the cutting speed on $\mathrm{F}_{\mathrm{t}}$ evolution for $r=0.8 \mathrm{~mm}$ and $f=0.16 \mathrm{~mm} / \mathrm{rev}$. Important values of $\mathrm{F}_{\mathrm{t}}$ are depicted also for higher cutting depth independently of cutting speed. Figure 7(d) illustrates the interaction of cutting speed and feed rate regarding $\mathrm{F}_{\mathrm{t}}$ evolution for $r=0.8 \mathrm{~mm}$ and $a_{p}=0.45 \mathrm{~mm}$. Here, the higher is both $V_{c}$ and $f$, the higher is $\mathrm{F}_{\mathrm{t}}$. It is known that tangential force values increase for undeformed chip thickness smaller than the cutting edge radius [7, 11]. This case induces higher specific cutting energy [21, 43].

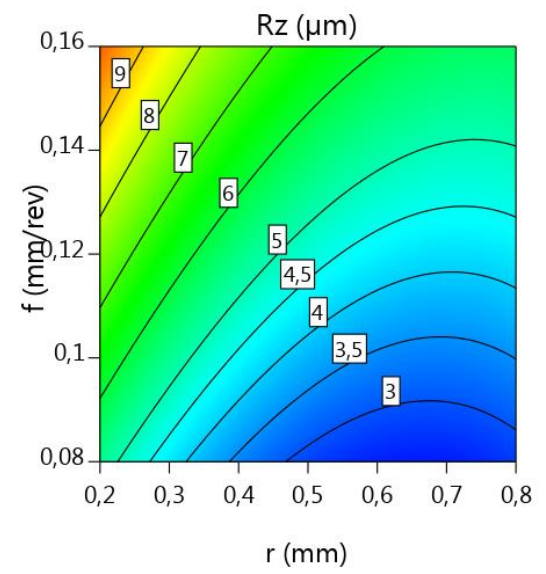

Figure 6. Effect of feed rate and nose radius on average peak-to-valley profile roughness evolution, with $V_{c}=80$ $\mathrm{m} / \mathrm{min} ; a_{p}=0.45 \mathrm{~mm}$

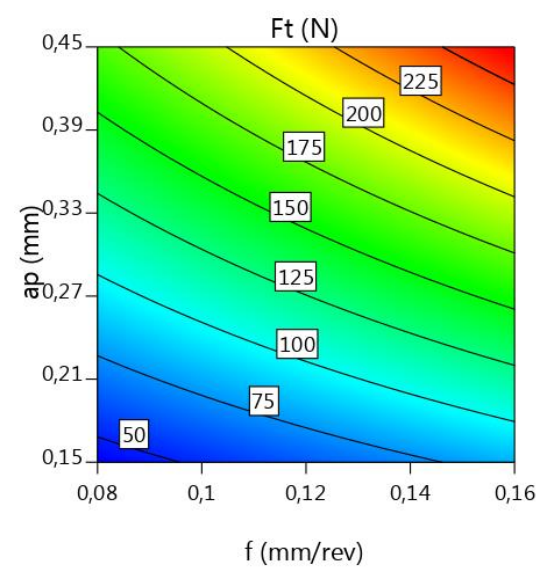

(a) $V_{c}=80 \mathrm{~m} / \mathrm{min}$ and $r=0.2 \mathrm{~mm}$

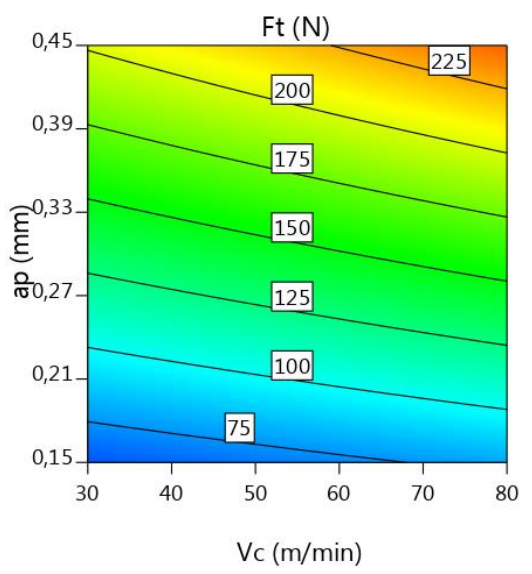

(c) $r=0.8 \mathrm{~mm}$ and $f=0.16 \mathrm{~mm} / \mathrm{rev}$

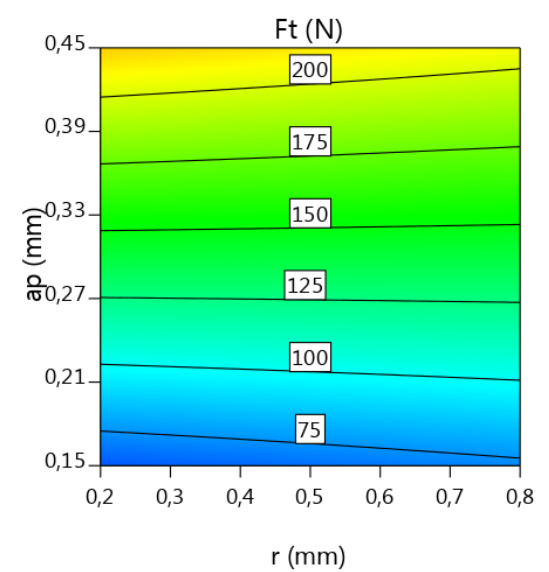

(b) $V_{c}=80 \mathrm{~m} / \mathrm{min}$ and $f=0.12 \mathrm{~mm} / \mathrm{rev}$

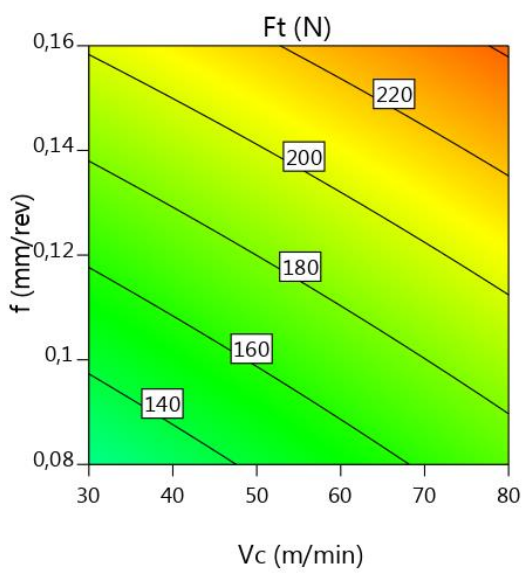

(d) $r=0.8 \mathrm{~mm}$ and $a_{p}=0.45 \mathrm{~mm}$

Figure 7. Effect of cutting conditions on tangential force evolution, 2D contours graphs 


\section{Confirmation Tests}

In order to confirm the validity of elaborated models of $R_{z}$ and $F_{t}$ when varying cutting parameters (for tool nose radius, $\mathrm{r}=0.8 \mathrm{~mm}$ ), additional tests were performed (Table 6). Results show that errors between experimental trials and developed mathematical models do not exceed $8.36 \%$ for $\mathrm{R}_{\mathrm{z}}$ and $8.66 \%$ for $\mathrm{F}_{\mathrm{t}}$. This finding demonstrates the effectiveness of developed models for the considered cutting conditions.

Table 6. Errors between experimental and estimated results in terms of average peak-to-valley profile roughness and tangential force (for $r=0.8 \mathrm{~mm}$ )

\begin{tabular}{ccccccccccc}
\hline & \multicolumn{3}{c}{ Cutting parameters } & \multicolumn{3}{c}{ Experimental } & \multicolumn{2}{c}{ Model } & \multicolumn{2}{c}{ Error $(\%)$} \\
\cline { 2 - 9 } Test & $V_{c}$ & $f$ & $a_{p}$ & $R_{z}$ & $F_{t}$ & $R_{z}$ & $F_{t}$ & $R_{z}$ & $F_{t}$ \\
& $(\mathrm{~mm} / \mathrm{min})$ & $(\mathrm{mm} / \mathrm{rev})$ & $(\mathrm{mm})$ & $(\mu \mathrm{m})$ & $(\mathrm{N})$ & $(\mu \mathrm{m})$ & $(\mathrm{N})$ & & \\
\hline 1 & 55 & 0.16 & 0.15 & 6.87 & 76.38 & 7.31 & 80.28 & 6.40 & 5.11 \\
2 & 55 & 0.20 & 0.15 & 8.75 & 96.7 & 9.30 & 97.87 & 6.29 & 1.21 \\
3 & 55 & 0.08 & 0.20 & 3.71 & 58.3 & 3.40 & 63.35 & 8.36 & 8.66 \\
4 & 55 & 0.08 & 0.30 & 3.82 & 88.52 & 3.53 & 95.83 & 7.59 & 8.26 \\
5 & 55 & 0.08 & 0.15 & 4.12 & 42.80 & 3.90 & 45.1 & 5.34 & 5.37 \\
6 & 110 & 0.08 & 0.15 & 3.32 & 49.93 & 3.20 & 53.9 & 3.61 & 7.95 \\
\hline
\end{tabular}

\section{Prediction of Responses using Artificial Neural Network (ANN)}

The ANNs is based on Neural Network toolbox, which is available in MATLAB Software. It is used to predict the $R_{z}$ and $F_{t}$ as a function of four input parameters: nose radius, cutting speed, feed rate and cutting depth.

Back-propagation algorithm and Levenberg-Marquadt (TRAINLM) were used as a learning algorithm and the TRANSIG (hyperbolic tangent sigmoid transfer function) as an activation function [44, 45]. The optimal ANN was composed of seven neurons in single hidden layer. The (4-7-1) architecture of ANN is illustrated in Figure 8. Two created networks are considered having the same architecture (4-7-1). They are used to predict an average peak-to-valley profile roughness and tangential force. The correlation between cutting parameters $\left(a_{p}, f, r\right.$ and $\left.V_{c}\right)$ and performance measurements, using the optimal ANN prediction of $R_{z}$ and $F_{t}$ by the Eqs. (2) and (3), respectively. Indeed, the output correlation coefficients $\left(\mathrm{R}^{2}\right)$ of the developed models, presented with the validation, test and overall graph in Figures 9 and 10 indicate the robust output correlation $\mathrm{R}^{2}$, which are $98.02 \%$ and $99.59 \%$ for $\mathrm{R}_{\mathrm{z}}$ and $\mathrm{F}_{\mathrm{t}}$, respectively. Therefore, it is important to note that the test sets are measure of generalisation for each network, although not for all of them, as the data that constitute a test set for a network are probably used for training or validation only. For this reason, the original data set was split into two parts, in order to ensure the preservation of a completely independent test set. The performance capability of the individual network was examined on the result of the correlation ratio between the network predictions and the experimental values using the original training, validation and test datasets. The performance of the prediction models for cutting force and surface roughness using the full training, validation and test datasets are presented in Figures 9 and 10.

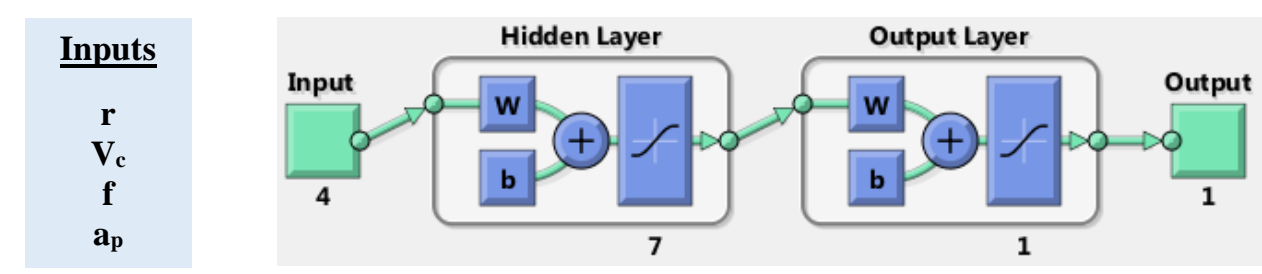

Figure 8. Architecture of neural network (Matlab ToolBox) 

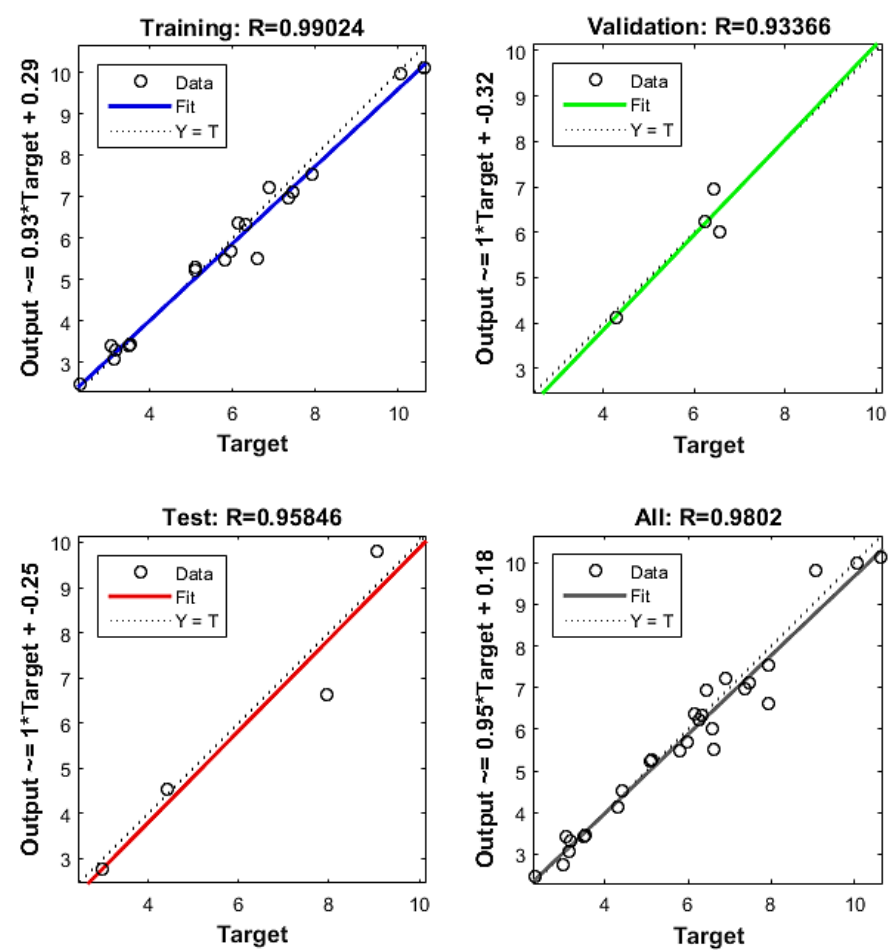

Figure 9. Training, Validation, Test and Overall graph for the correlation coefficient for average peak-to-valley profile roughness
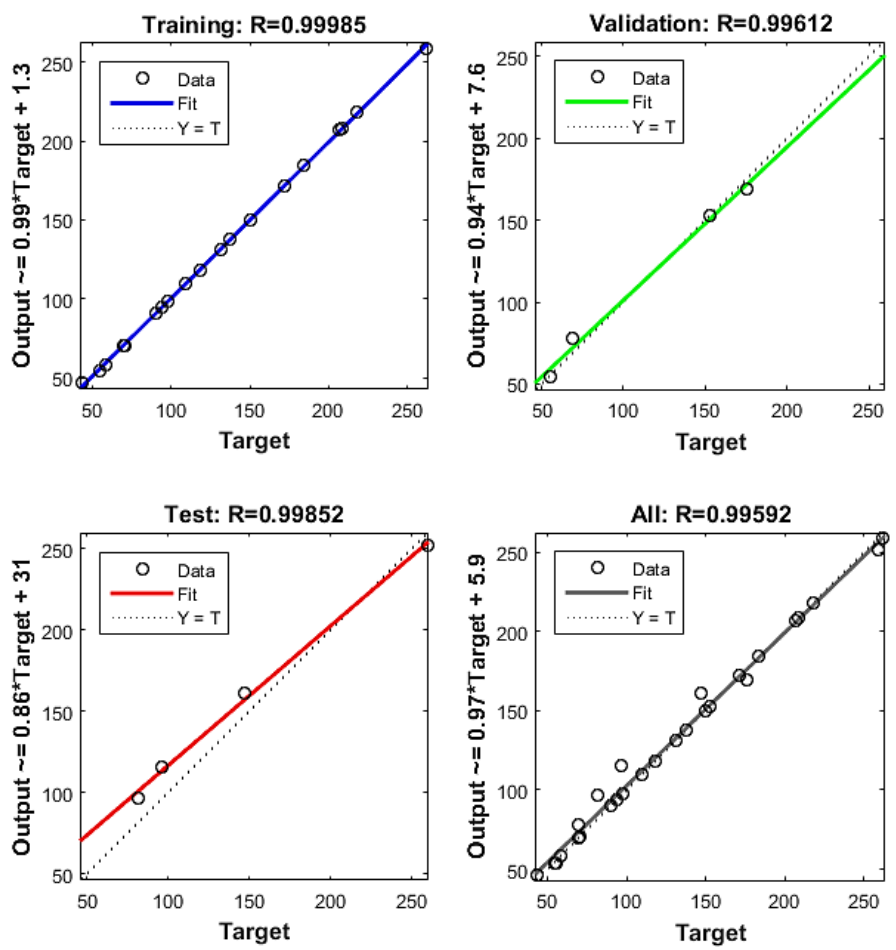

Figure 10. Training, Validation, Test and Overall graph for the correlation coefficient for tangential force

\section{Prediction of Responses using SVM Approach}

SVM's, also called "wide margin separators" are binary classification methods by supervised learning techniques designed to solve classification problems inspired by the statistical theory of learning. SVM are the best-known form of kernel methods $[26,27]$. They are based on the use of kernel functions allowing an optimal separation of data. 
The intuitive justification for this learning is valid when learning sample is linearly separable. The linear function is formulated with Eq. (4):

$$
y(x)=\omega^{T} \varphi(x)+b
$$

Where $y(x)$ is called the characteristic function and $\varphi(x)$ is the correctly classifying all observations in the learning set. $\omega$ is a weight vector and $b$ is a bias which is evaluated by the minimization of Eq. (5):

$$
R(c)=C \frac{1}{n} \sum_{i=1}^{n} L\left(d_{i} \cdot y_{i}\right)+\frac{1}{2}\left\|\omega^{2}\right\|
$$

$\mathrm{L}\left(\mathrm{d}_{\mathrm{i}} \cdot \mathrm{y}_{\mathrm{i}}\right)$ is called the $\varepsilon$-intensive loss function and indicates that errors below $\varepsilon$ are not penalized. The term $\mathrm{C} \frac{1}{\mathrm{n}} \sum_{\mathrm{i}=1}^{\mathrm{n}} \mathrm{L}\left(\mathrm{d}_{\mathrm{i}} \cdot \mathrm{y}_{\mathrm{i}}\right)$ is the empirical error, $\frac{1}{2}\left\|\omega^{2}\right\|$ is a measure of the smoothness of the function. $\mathrm{C}$ is the regularization constant and $\varepsilon$ is the SVM tube size.

The success of this method is justified by the solid foundations that support it. They can be used to address various classification issues. SVM is a particularly well adapted method for processing very large data.

In order to estimate the experimental results $\left(R_{z}\right.$ and $\left.F_{t}\right)$, the SVM model was formed with 27 experimental data, as shown in Table 7. In this model, four parameters were selected as inputs $\left(r, V_{c}, f\right.$ and $\left.a_{p}\right)$, while the outputs was also $R_{z}$ and $\mathrm{F}_{\mathrm{t}}$.

The SVM model was developed using RapidMiner Software. For each type of SVM model developed, few different kernel functions have been applied to analyze the best kernel leads to the best result. For best SVM model performance, a non-linear kernel (kernel type, radial) was selected due to the non-linear machining process. The optimized parameters SVM such as regularization constant $(C=5000)$ and the tube size $(\varepsilon=0.02)$, have been used to obtain the best SVM output. SVM models are constructed separately by using the experimental data.

\begin{tabular}{|c|c|c|c|c|c|c|c|c|c|c|c|c|}
\hline \multirow{2}{*}{ Run } & \multirow{2}{*}{$\begin{array}{c}r \\
(\mathrm{~mm})\end{array}$} & \multirow{2}{*}{$\begin{array}{c}V_{c} \\
(\mathrm{~m} / \mathrm{min})\end{array}$} & \multirow{2}{*}{$\begin{array}{c}f \\
(\mathrm{~mm} / \mathrm{rev})\end{array}$} & \multirow{2}{*}{$\begin{array}{c}a_{p} \\
(\mathrm{~mm})\end{array}$} & \multicolumn{4}{|c|}{$R_{z}(\mu m)$} & \multicolumn{4}{|c|}{$F_{t}(N)$} \\
\hline & & & & & EXP & RSM & ANN & SVM & EXP & RSM & ANN & SVM \\
\hline 1 & 0.2 & 30 & 0.08 & 0.15 & 5.11 & 5.21 & 5.09 & 5.10 & 43.00 & 45.36 & 46.78 & 43.07 \\
\hline 2 & 0.2 & 30 & 0.08 & 0.30 & 5.81 & 5.66 & 5.83 & 5.81 & 94.00 & 87.86 & 94.20 & 93.94 \\
\hline 3 & 0.2 & 30 & 0.08 & 0.45 & 6.25 & 6.30 & 6.54 & 6.25 & 147.40 & 151.18 & 161.52 & 147.41 \\
\hline 4 & 0.2 & 55 & 0.12 & 0.15 & 7.46 & 7.23 & 7.44 & 7.45 & 70.00 & 70.63 & 69.82 & 70.01 \\
\hline 5 & 0.2 & 55 & 0.12 & 0.30 & 7.94 & 7.37 & 7.04 & 7.94 & 131.20 & 132.88 & 131.63 & 131.19 \\
\hline 6 & 0.2 & 55 & 0.12 & 0.45 & 6.90 & 7.70 & 6.85 & 6.90 & 218.20 & 215.95 & 218.43 & 218.24 \\
\hline 7 & 0.2 & 80 & 0.16 & 0.15 & 10.65 & 10.00 & 10.20 & 10.64 & 82.00 & 83.07 & 96.97 & 82.04 \\
\hline 8 & 0.2 & 80 & 0.16 & 0.30 & 9.07 & 9.86 & 9.13 & 9.08 & 171.60 & 165.08 & 171.94 & 171.61 \\
\hline 9 & 0.2 & 80 & 0.16 & 0.45 & 10.06 & 9.88 & 10.05 & 10.06 & 262.40 & 267.89 & 258.84 & 262.41 \\
\hline 10 & 0.4 & 30 & 0.12 & 0.15 & 5.09 & 5.65 & 5.04 & 5.11 & 55.50 & 56.38 & 54.21 & 55.52 \\
\hline 11 & 0.4 & 30 & 0.12 & 0.30 & 6.60 & 6.02 & 6.60 & 6.59 & 109.60 & 109.39 & 109.46 & 109.60 \\
\hline 12 & 0.4 & 30 & 0.12 & 0.45 & 6.57 & 6.59 & 6.61 & 6.57 & 183.90 & 183.21 & 184.47 & 183.87 \\
\hline 13 & 0.4 & 55 & 0.16 & 0.15 & 6.44 & 7.11 & 6.57 & 6.45 & 90.50 & 87.79 & 90.48 & 90.55 \\
\hline 14 & 0.4 & 55 & 0.16 & 0.30 & 7.35 & 7.17 & 7.29 & 7.34 & 152.70 & 160.55 & 153.07 & 152.75 \\
\hline 15 & 0.4 & 55 & 0.16 & 0.45 & 7.92 & 7.42 & 7.92 & 7.93 & 259.20 & 254.12 & 251.59 & 259.16 \\
\hline 16 & 0.4 & 80 & 0.08 & 0.15 & 3.07 & 3.27 & 3.00 & 3.08 & 54.40 & 52.05 & 53.98 & 54.37 \\
\hline 17 & 0.4 & 80 & 0.08 & 0.30 & 3.18 & 3.18 & 2.90 & 3.17 & 96.70 & 101.92 & 115.64 & 96.56 \\
\hline 18 & 0.4 & 80 & 0.08 & 0.45 & 3.49 & 3.28 & 3.43 & 3.49 & 175.60 & 172.59 & 169.30 & 175.63 \\
\hline 19 & 0.8 & 30 & 0.16 & 0.15 & 5.96 & 5.81 & 5.92 & 5.96 & 69.30 & 65.28 & 78.05 & 69.34 \\
\hline 20 & 0.8 & 30 & 0.16 & 0.30 & 6.32 & 6.07 & 6.33 & 6.33 & 118.30 & 125.08 & 118.45 & 118.26 \\
\hline 21 & 0.8 & 30 & 0.16 & 0.45 & 6.15 & 6.53 & 3.79 & 6.15 & 208.50 & 205.69 & 208.49 & 208.45 \\
\hline 22 & 0.8 & 55 & 0.08 & 0.15 & 2.98 & 2.63 & 2.75 & 2.99 & 58.40 & 58.40 & 58.18 & 58.43 \\
\hline
\end{tabular}

Table 7. Experimental and prediction results for RSM, ANN and SVM during the turning operation of Stellite 6 material 
Table 7. Experimental and prediction results for RSM, ANN and SVM during the turning operation of Stellite 6 material (cont.)

\begin{tabular}{|c|cccc|cccc|cccc|}
\hline \multirow{2}{*}{ Run } & $r$ & $V_{c}$ & $f$ & $a_{p}$ & \multicolumn{5}{|c|}{$R_{z}(\mu m)$} & \multicolumn{4}{c|}{$F_{t}(N)$} \\
& $(\mathrm{mm})$ & $(\mathrm{m} / \mathrm{min})$ & $(\mathrm{mm} / \mathrm{rev})$ & $(\mathrm{mm})$ & EXP & RSM & ANN & SVM & EXP & RSM & ANN & SVM \\
\hline 23 & 0.8 & 55 & 0.08 & 0.30 & 2.30 & 2.74 & 2.44 & 2.31 & 98.00 & 95.30 & 98.10 & 97.97 \\
24 & 0.8 & 55 & 0.08 & 0.45 & 3.13 & 3.04 & 3.13 & 3.14 & 150.30 & 153.02 & 150.22 & 150.33 \\
25 & 0.8 & 80 & 0.12 & 0.15 & 4.43 & 4.22 & 4.61 & 4.43 & 70.40 & 74.70 & 70.23 & 70.37 \\
26 & 0.8 & 80 & 0.12 & 0.3 & 3.52 & 4.01 & 3.53 & 3.52 & 137.50 & 131.35 & 137.77 & 137.55 \\
27 & 0.8 & 80 & 0.12 & 0.45 & 4.29 & 4.00 & 3.32 & 4.27 & 207.00 & 208.82 & 206.94 & 206.96 \\
\hline
\end{tabular}

\section{COMPARATIVE OF PROCESS RESPONSES WITH RSM ANN AND SVM}

RSM, ANN, SVM experimental, and prediction results presented in Table 7. A comparison can be made using three indicators namely, coefficient of determination $\left(R^{2}\right)$ (Eq. (6)), the model predictive error (MPE) (Eq. (7)) and root mean square error (RMSE) (Eq. (8))

$$
\begin{gathered}
R^{2}=1-\frac{\sum_{i=1}^{n}\left(y_{i . p r e d}-y_{i . e x p}\right)^{2}}{\sum_{i=1}^{n}\left(y_{i . p r e d}-y_{\text {average }}\right)^{2}} \\
M P E(\%)=\frac{100}{n} \sum_{i=1}^{n}\left|\frac{\left(y_{i . \text { exp }}-y_{\text {i.pred }}\right)}{y_{\text {i.pred }}}\right| \\
R M S E=\sqrt{\frac{\sum_{i=1}^{n}\left(y_{i, \text { exp }}-y_{i, \text { pred }}\right)^{2}}{n}}
\end{gathered}
$$

where $\mathrm{n}$ is the experiments number, $y_{i . p r e d}$ and $y_{i . \exp }$ are the predicted and experimental values of the ith experiment, respectively and $y_{\text {average }}$ is the average value.

The correlation coefficient $\left(\mathrm{R}^{2}\right)$ values for the average peak-to-valley profile roughness $\left(\mathrm{R}_{\mathrm{z}}\right)$ using RSM. ANN and SVM approaches are 0.9506, 0.9802 and 0.9997, respectively (Table 8). Moreover, SVM model presents a good model predictive error MPE (\%) value (0.15) compared with the RSM (6.03) and ANN models (5.66). This comparison it is clearly presented in Figure 10. Also, it is very clear that SVM approach has higher performance when compared with ANN and RSM. Indeed, this performance can be depicted using root mean square error RMSE values for RSM (value equals to 0.40), ANN (value equals to 0.54) and SVM (value equals to 0.008).

The SVM model presents a good coefficient of determination $\left(R^{2}\right)$ values for tangential cutting force $\left(\mathrm{F}_{\mathrm{t}}\right)$ using RSM, ANN and SVM models are 0.9956, 0.9959 and 0.9999, respectively (Table 8). In addition, the adopted SVM model presents a good model predictive error (MPE) value (0.04) compared with the ANN approach (2.74) and RSM method (2.87) (Table 8).

The predictor RMSE (\%) values find that the SVM is the good model compared with RSM and ANN models. These values are 0.76, 1.16 and 0.009 , respectively. Figure 10 shows the comparison with observed values and the estimated values using RSM, ANN and SVM modelling for $F_{t}$. Similarly, the values obtained with three predictors (Table 8) shows that the SVM model is the adequate one when compared with RSM and ANN.

Table 8. Values for predictors $\mathrm{R}^{2}$, RMSE (\%) and MPE (\%) for RSM ANN and SVM approaches

\begin{tabular}{cccccccccc}
\hline \multirow{3}{*}{ Response } & \multicolumn{3}{c}{$R S M$} & \multicolumn{3}{c}{$A N N$} & \multicolumn{3}{c}{$S V M$} \\
\cline { 2 - 10 } & $R^{2}$ & $\begin{array}{c}R M S E \\
(\%)\end{array}$ & $\begin{array}{c}M P E \\
(\%)\end{array}$ & $R^{2}$ & $\begin{array}{c}\text { RMSE } \\
(\%)\end{array}$ & $\begin{array}{c}M P E \\
(\%)\end{array}$ & $R^{2}$ & $\begin{array}{c}\text { RMSE } \\
(\%)\end{array}$ & $\begin{array}{c}M P E \\
(\%)\end{array}$ \\
\hline$R_{z}(\mu \mathrm{m})$ & 0.9506 & 0.40 & 6.03 & 0.9802 & 0.54 & 5.66 & 0.9997 & 0.008 & 0.15 \\
$F_{t}(N)$ & 0.9956 & 0.76 & 2.87 & 0.9959 & 1.16 & 2.74 & 0.9999 & 0.009 & 0.04 \\
\hline
\end{tabular}



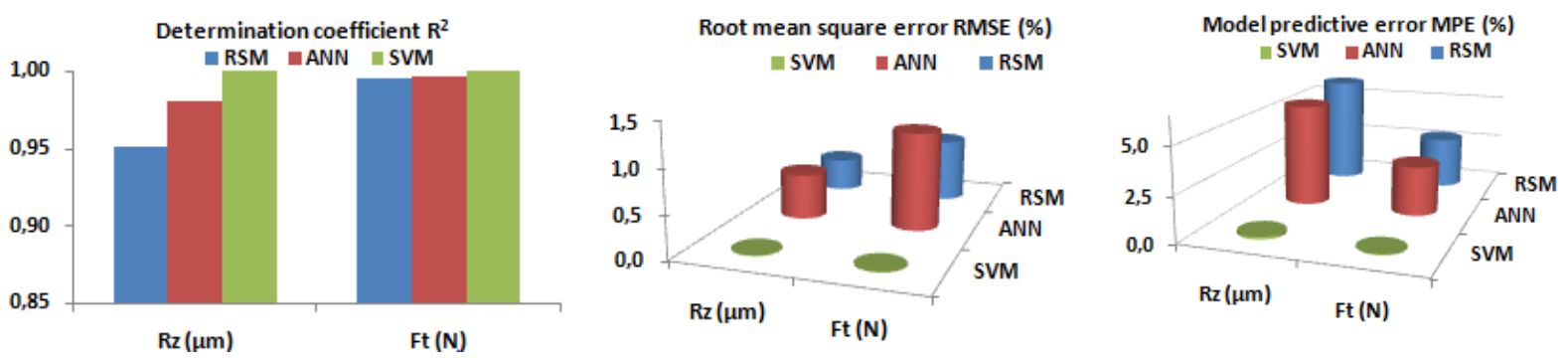

Figure 11. Graphic representation for three predictors $\mathrm{R}^{2}$, RMSE (\%) and MPE (\%)

\section{CONCLUSIONS}

Modelling techniques of outputs according to the variations of operating parameters (nose radius, cutting depth, cutting speed and feed rate) in straight turning of Stellite 6 were presented. These techniques concern RSM, SVM and ANN which were exploited successfully to model evolutions of average peak-to-valley profile roughness and tangential force.

The results showed that both feed rate and nose radius are the most significant factor affecting average value of peak-to-valley roughness closely followed by cutting depth and cutting speed. For tangential force, it can be underlined that its evolution is highly affected by both cutting depth and feed rate.

An increase of the microgeometrical characterics is clearly the result of higher nose radius and the smaller feed rate. The evolution of tangential force depend considerably on cutting depth and cutting speed variations. In addition, it can be, on the one hand, it can be pointed out that higher levels of tangential force depend on both increasing depth of cut and increasing feed rate. On the other hand, lower tangential force values are shown as the feed rate and depth of cut decrease. This is due to lower chip section. For cutting parameters $\mathrm{Vc}=80 \mathrm{~m} / \mathrm{min}$ and $\mathrm{f}=0.12 \mathrm{~mm} / \mathrm{rev}$, it can be noted a slight effect of the nose radius on tangential force evolution. Important values of tangential force are depicted for the higher cutting depth independently of the nose radius which is the result, among others, of material hardening caused by higher cutting depth.

The two new models showing the evolution of average peak-to-valley profile roughness and tangential force based on RSM provide effective guidelines for selecting appropriate cutting parameters to achieve desired surface roughness and associate tangential force for straight turning of Stellite 6. The significant impact of the cutting parameters on the tangential force $\left(\mathrm{F}_{\mathrm{t}}\right)$ can illustrate that cutting depth is the most significant factor with $(76.03 \%)$ contribution. The computational model that was developed in the study can be improved in the future for the investigation of more other parameters charachterising turning operations.

\section{ACKNOWLEDGEMENTS}

This study was carried out in the framework of a collaboration between both laboratories (LMAI - ENIT - El Manar University - Tunisia and LMS - University 8 May 1945 Guelma - Algeria. We sincerely thank to Paradigm Precision - EUROCAST for their support during this project.

\section{REFERENCES}

[1] J. Sato, T. Omori, K. Oikawa, I. Ohnuma, R. Kainuma, and K. Ishida, "Cobalt-base high-temperature alloys,” Science, vol. 312, no. 5770, pp. 90-91, 2006.

[2] L. E. Davis, N. C. MacDonald, P. W. Palmberg, G. E. Riach, and R. E. Weber, Nickel, cobalt, and their alloys. Physical Electronics Industries, Inc., 1976.

[3] V. Kuzucu, M. Ceylan, H. Çelik, and I. Aksoy, “An investigation of stellite-6 alloy containing 5.0 wt\% silicon,” J. Mater. Process. Technol., vol. 79, no. 1-3, pp. 47-51, 1998.

[4] J. L. Murray, “The Co-Ti (Cobalt-Titanium) system,” Bull. Alloy Phase Diagrams, vol. 3, no. 1, pp. 74-85, 1982.

[5] E. O. Ezugwu, "Key improvements in the machining of difficult-to-cut aerospace superalloys," Int. J. Mach. Tools Manuf., vol. 45, no. 12-13, pp. 1353-1367, 2005.

[6] E. O. Ezugwu, J. Bonney, and Y. Yamane, "An overview of the machinability of aeroengine alloys," J. Mater. Process. Technol., vol. 134, no. 2, pp. 233-253, 2003.

[7] S. H. Lee, E. Takahashi, N. Nomura, and A. Chiba, "Effect of heat treatment on microstructure and mechanical properties of Ni- And C-Free Co-Cr-Mo alloys for medical applications," Mater. Trans., vol. 46, no. 8, pp. 1790-1793, 2005.

[8] B. Ben Fathallah, C. Braham, and H. Sidhom, "Combined effects of abrasive type and cooling mode on fatigue resistance of AISI D2 ground surface,” Int. J. Fatigue, vol. 138, p. 105665, 2020.

[9] A. Javidi, U. Rieger, and W. Eichlseder, "The effect of machining on the surface integrity and fatigue life," Int. J. Fatigue, vol. 30, no. 10-11, pp. 2050-2055, 2008. 
[10] H. A. Zaman, S. Sharif, D. W. Kim, M. H. Idris, M. A. Suhaimi, and Z. Tumurkhuyag, "Machinability of Cobalt-based and Cobalt Chromium Molybdenum Alloys - A Review," Procedia Manuf., vol. 11, pp. 563-570, 2017.

[11] A. Bordin, S. Bruschi, and A. Ghiotti, "The effect of cutting speed and feed rate on the surface integrity in dry turning of CoCrMo alloy," in Procedia CIRP, vol. 13, pp. 219-224, 2014.

[12] G. Yingfei, P. M. de Escalona, and A. Galloway, "Influence of cutting parameters and tool wear on the surface integrity of Cobalt-Based stellite 6 alloy when machined under a dry cutting environment," J. Mater. Eng. Perform., vol. 26, no. 1, pp. 312-326, 2017.

[13] A. Bordin, S. Bruschi, and A. Ghiotti, "The effect of cutting speed and feed rate on the surface integrity in dry turning of CoCrMo alloy," in Procedia CIRP, vol. 13, pp. 219-224, 2014.

[14] M. Sarikaya and A. Güllü, "Multi-response optimization of minimum quantity lubrication parameters using Taguchi-based grey relational analysis in turning of difficult-to-cut alloy Haynes 25," J. Clean. Prod., vol. 91, pp. 347-357, 2015.

[15] B. Ben Fathallah, R. Saidi, T. Mabrouki, S. Belhadi, and M. A. Yallese, "Multi-optimization of stellite 6 turning parameters for better surface quality and higher productivity through RSM and grey relational analysis," in Lecture Notes in Mechanical Engineering, pp. 382-391, 2021.

[16] E. Bagci and Ş. Aykut, "A study of Taguchi optimization method for identifying optimum surface roughness in CNC face milling of cobalt-based alloy (stellite 6)," Int. J. Adv. Manuf. Technol., vol. 29, no. 9-10, pp. 940-947, 2006.

[17] M. Sarikaya and A. Güllü, "Examining of tool wear in cryogenic machining of Cobalt-Based Haynes 25 superalloy," Int. J. of Chem. Mol. Nuc., Mat. and Metall. Eng., vol. 9, no. 8, 2015.

[18] R. Saidi, B. B. Fathallah, T. Mabrouki, S. Belhadi, and M. A. Yallese, "Modeling and optimization of the turning parameters of cobalt alloy (Stellite 6) based on RSM and desirability function," Int. J. Adv. Manuf. Technol., vol. 100, no. 9-12, pp. 29452968, 2019.

[19] Ş. Aykut, E. Bagci, A. Kentli, and O. Yazicioğlu, "Experimental observation of tool wear, cutting forces and chip morphology in face milling of cobalt based super-alloy with physical vapour deposition coated and uncoated tool," Mater. Des., vol. 28 , no. 6, pp. 1880-1888, 2007.

[20] Ş. Aykut, M. Gölcü, S. Semiz, and H. S. Ergür, "Modeling of cutting forces as function of cutting parameters for face milling of satellite 6 using an artificial neural network," J. Mater. Process. Technol., vol. 190, no. 1-3, pp. 199-203, 2007.

[21] E. Bağc1 and Ş. Aykut, "The effects of tool position, coating and cutting parameters on forces, power, MRR and wear in face milling of stellite 6," Arab. J. Sci. Eng., vol. 39, no. 11, pp. 8135-8146, 2014.

[22] B. Ben Fathallah, R. Saidi, T. Mabrouki, S. Belhadi, and M. A. Yallese, "Multi-optimization of stellite 6 turning parameters for better surface quality and higher productivity through RSM and grey relational analysis", In Book: Desg. and Mod. of Mech. Sys., pp. 382-391, 2020.

[23] Ş. Aykut, A. Kentli, S. Gülmez, and O. Yazıcıŏlu, "Robust multiobjective optimization of cutting parameters in face milling," Acta Polytechnica Hungarica, vol. 9, no. 4, 2012.

[24] B. Ben Fathallah, R. Saidi, C. Dakhli, S. Belhadi, and M. A. Yallese, "Mathematical modelling and optimization of surface quality and productivity in turning process of AISI 12L14 free-cutting steel," Int. J. Ind. Eng. Comput., vol. 10, no. 4, pp. 557576, 2019.

[25] R. Saidi, B. Ben Fathallah, T. Mabrouki, S. Belhadi, and M. A. Yallese, "Prediction of forces components during the turning process of stellite 6 material based on artificial neural networks," in Lecture Notes in Mechanical Engineering, pp. 399-408, 2020.

[26] M. Sarikaya and A. Güllü, "Taguchi design and response surface methodology based analysis of machining parameters in CNC turning under MQL,” J. Clean. Prod., vol. 65, pp. 604-616, 2014.

[27] V. N. Vapnik, The Nature of Statistical Learning Theory. Springer New York, 2000.

[28] V. Vapnik and O. Chapelle, "Bounds on error expectation for support vector machines," Neural Comput., vol. 12, no. 9, pp. 2013-2036, 2000.

[29] V. N. Vapnik and V. N. Vapnik, "Direct methods in statistical learning theory," in The Nature of Statistical Learning Theory, Springer New York, pp. 225-265, 2000.

[30] V. N. Vapnik and A. Y. Chervonenkis, "On the uniform convergence of relative frequencies of events to their probabilities," in Measures of Complexity: Festschrift for Alexey Chervonenkis, Springer International Publishing, 2015, pp. 11-30.

[31] B. E. Boser, B. E. Boser, I. M. Guyon, and V. N. Vapnik, "A training algorithm for optimal margin classifiers," Proc. $5^{\text {th }}$ Annu. ACM Work. Comput. Learn. THEORY, pp. 144-152, 1992.

[32] C. Cortes and V. Vapnik, "Support-vector networks," Mach. Learn., vol. 20, no. 3, pp. 273-297, 1995.

[33] A. K. Gupta, S. C. Guntuku, R. K. Desu, and A. Balu, "Optimisation of turning parameters by integrating genetic algorithm with support vector regression and artificial neural networks," Int. J. Adv. Manuf. Technol., vol. 77, no. 1-4, pp. 331-339, 2015 .

[34] C. Karataş, A. Sozen, and E. Dulek, "Modelling of residual stresses in the shot peened material C-1020 by artificial neural network," Expert Syst. Appl., vol. 36, no. 2 PART 2, pp. 3514-3521, 2009.

[35] A. K. Gupta, "Predictive modelling of turning operations using response surface methodology, artificial neural networks and support vector regression," Int. J. Prod. Res., vol. 48, no. 3, pp. 763-778, 2010.

[36] S. Vadlamani and S. Hosseini, "A novel heuristic approach for solving aircraft landing problem with single runway," J. Air Transp. Manag., vol. 40, pp. 144-148, 2014. 
[37] M. Mohammadnejad, R. Gholami, A. Ramezanzadeh, and M. Jalali, "Prediction of blast-induced vibrations in limestone quarries using Support Vector Machine,” J. Vib. Control, vol. 18, no. 9, pp. 1322-1329, 2012.

[38] K. Venkata Subbaiah, C. Raju, and C. Suresh, "Parametric analysis and optimization of hard turning at different levels of hardness using wiper ceramic insert," Meas. J. Int. Meas. Confed., vol. 158, 2020.

[39] K. Venkata Rao, B. S. N. Murthy, and N. Mohan Rao, "Prediction of cutting tool wear, surface roughness and vibration of work piece in boring of AISI 316 steel with artificial neural network," Meas. J. Int. Meas. Confed., vol. 51, no. 1, pp. 63-70, 2014.

[40] M. M. De Aguiar, A. E. Diniz, and R. Pederiva, "Correlating surface roughness, tool wear and tool vibration in the milling process of hardened steel using long slender tools," Int. J. Mach. Tools Manuf., vol. 68, pp. 1-10, 2013.

[41] S. Belhadi, M. Kaddeche, K. Chaoui, and M.-A. Yallese, "Machining optimization of HDPE pipe using the Taguchi method and grey relational analysis," Int. Polym. Process., vol. 31, no. 4, pp. 491-502, 2016.

[42] H. A. Zaman, S. Sharif, D-W. Kim, M.H. Idris, M.A. Suhaimi, Z. Tumurkhuyag, "Machinability of cobalt-based and cobalt chromium molybdenum alloys-A review," Proc Manuf, vol. 11, pp. 563-570, 2017.

[43] S. C. Agarwal and H. Ocken, "The microstructure and galling wear of a laser-melted cobalt-base hardfacing alloy," Wear, vol. 140, no. 2, pp. 223-233, 1990.

[44] L. Bouzid, S. Boutabba, M. A. Yallese, S. Belhadi, and F. Girardin, "Simultaneous optimization of surface roughness and material removal rate for turning of X20Cr13 stainless steel," Int. J. Adv. Manuf. Technol., vol. 74, no. 5-8, pp. 879-891, 2014.

[45] L. Bouzid, M. A. Yallese, S. Belhadi, and A. Haddad, "Modelling and optimization of machining parameters during hardened steel AISID3 turning using RSM, ANN and DFA techniques: Comparative study," J. Mech. Eng. Sci., vol. 14, no. 2, pp. 68356847, 2020. 